\title{
Recent Advances in Finite Element Applications in Artificial Lumbar Disc Replacement
}

\author{
Zhenjun Zhang1, Yitao Sun², Xuejun Sun³, Yang Li', Zhenhua Liao, ${ }^{1,4}$, Weiqiang Liư ${ }^{1,4}$ \\ ${ }^{1}$ Department of Mechanical Engineering, Tsinghua University, Beijing, China \\ ${ }^{2}$ Haicheng City Central Hospital, Haicheng, China \\ ${ }^{3}$ Beijing Yingnuanlihe Technologies Co., Ltd., Beijing, China \\ ${ }^{4}$ Shenzhen Institute of Tsinghua University, Laboratory of Biomedical Material and Implanted Devices, Shenzhen, China \\ Email: weiqliu@hotmail.com
}

How to cite this paper: Zhang, Z.J., Sun, Y.T., Sun, X.J., Li, Y., Liao, Z.H. and Liu, W.Q. (2016) Recent Advances in Finite Element Applications in Artificial Lumbar Disc Replacement. J. Biomedical Science and Engineering, 9, 1-8.

http://dx.doi.org/10.4236/jbise.2016.910B001

Received: April 1, 2016

Accepted: September 20, 2016

Published: September 23, 2016

\begin{abstract}
As a new choice for the treatment of degenerative lumbar disease, artificial lumbar disc replacement has been widely used in clinical surgery. The finite element is a very effective method to predict and simulate the surgery effect. The purpose of this paper is to review the applications of finite element in artificial lumbar disc replacement, such as design of artificial lumbar disc prosthesis, risk and effect evaluation of artificial lumbar disc replacement, and assessment of operation methods. Lastly, we discuss the future development of finite element method applied in this field, including personalized design of the prosthesis, postoperative behavior guide, and artificial lumbar disc replacement combined with fusion surgery. In conclusion, as an invaluable complement to biomechanical experiments and clinical studies, the finite element method makes important contributions to our understanding of biomechanics of intervertebral disc, and plays an important role in the field of artificial lumbar disc replacement.
\end{abstract}

\section{Keywords}

Finite Element, Artificial Lumbar Disc, Artificial Lumbar Disc Prosthesis, Artificial Lumbar Disc Replacement

\section{Introduction}

The basic idea of artificial disc replacement is to minimize the impact on adjacent segments by stabilizing degenerative segment, then preventing and reducing the incidence of adjacent segment degeneration [1]. In theory, lumbar disc arthroplasty better suits the needs of the human body. It has become a research hotspot in the field of spine 
surgery [2]. Van Steenbrugghe [3] proposed the concept of the intervertebral disc prosthesis for the first time in 1956. The two main types of total lumbar disc prosthesis were designed in the 1980s: Charité and ProDisc. As spine biomechanics, kinematics, materials science and other related disciplines developed, the techniques of artificial lumbar disc advanced greatly.

The finite element method (FEM) is a numerical technique for finding approximate solutions to boundary value problems for partial differential equations. Brekelmans et al. [4] applied this method to the field of biomechanics in 1972. Belytshko et al. [5] established 2-D finite element model of intervertebral disc for the first time in 1974. Over the next 40 years, the method has a rapid development. The development direction of spinal finite element model is as follows: from 2-D model to 3-D model, from the linear single material to nonlinear composite material, from an activity segment to full lumbar segment [6]-[9]. The morphology and mechanical properties of finite element model are closer to the anatomy of a normal human body, and the simulation results are closer to the experimental results in vitro.

By reviewing the development situation and related problems of the finite element applications in artificial lumbar disc replacement, we aim to provide guidance for future design of artificial lumbar disc prosthesis, preoperative risk assessment, prevention of postoperative complications, and choice of surgical implementation plan.

\section{Recent Advances}

\subsection{Design of Artificial Lumbar Disc Prosthesis}

The development of artificial lumbar disc prosthesis requires several in vitro methods to realize: finite element analysis, specimen mechanics experiment, the friction and wear experiment, and animal experiments, to improve and determine its rationality and safety. Finite element analysis plays an important role for the research of spine structure and function. An artificial lumbar disc model is created using computer simulation with boundary conditions and load conditions applied. From which the analysis results of different materials and structures can be determined. In particular, the stress and strain analysis of complex system can be obtained efficiently by using the finite element method. The methods of finite element can provide effective support for the design and application of artificial lumbar disc prosthesis.

Ge Lei and Li Kanghua [10] analyzed the stress of artificial disc prosthesis under positive pressure by finite element method and different material set, aimed to optimize the structure of some mechanical part. The experiment discussed the possibility and effectiveness of structure and material optimization of existing artificial disc prosthesis on the basis of the related mechanics analysis. In Warsaw University of Technology, Oleguer Sans i Ballart [11] made a parametric design of an artificial lumbar disc using finite element software (ANSYS) in APDL language (ANSYS parametric design language), and then used the software to study the structural response of the intervertebral disc in different situations. The conclusion was that the inlay brim needs to have a greater thickness in order for the prosthesis to achieve proper operation. If the inlay 
brim is reduced, the artificial disc will not work properly producing several instability problems and will become a hazard to the patient's body that may be more harmful than beneficial. P. Borkowski et al. [12] presented the application of finite element method in an artificial disc modeling. The prosthesis consisted of two metal plates and a flexible elastomeric core made of the nanocomposite polyurethane. For some analyzed cases (except the axial rotation and shear, where the prosthesis was too flexible) the results were roughly similar to those observed in the human spinal segment. F. García Vacas et al. [13] presented a novel disc prosthesis that can function as either a constrained or an unconstrained design. A calibrated finite element model of the L4 - L5 lumbar segment was used to compare the lumbar segment biomechanics in the sagittal plane when either the new design or a typical ball-and-socket design were implanted. The ligament and facet forces as well as the location of the instantaneous centre of rotation found that the constrained configuration of the new prosthesis are closer to the natural physiological conditions than those predicted with the ball-and-socket prosthesis. The conclusion of their study is that the use of the unconstrained configuration of the new design results in a further reduction in the ligament and facet forces.

By using three-dimensional finite element method (FEM), the mechanical properties of artificial disc prostheses can be obtained through the simulated body condition and simple physical experiment, so as to reflect the mechanical changes of an artificial disc in the physiological and pathological processes. The finite element method can be used to analyze the stress and strain of components with complex morphology, structure, material and loading condition, so it has the advantages of comprehensive mechanical properties, repeatability and high-level controllability [14]. However, the finite element method still needs to be improved in the following areas: simulation of dynamic physiological process, connection and relationship between complex organizations, influence of muscle and other relevant factors on the stability of lumbar muscles, and standardization of model structure and materials.

\subsection{Risk and Effect Evaluation of Artificial Lumbar Disc Replacement}

With the development of spinal biomechanics, artificial lumbar disc replacement is considered to be a good choice for treating degenerative lumbar spine disease. Artificial lumbar discs can maintain the motion and load bearing function of operative segment, and retain the stability and activity of lumbar spine [15]. To avoid the risk of degenerative cascade, the total disc replacement (TDR) may be considered as an alternative in some specific cases. The clinical objectives of TDR include pain relief and functional recovery with an acceptable level of comorbidity and an early return to daily activities [16].

Wang Hua et al. [15] established the three-dimensional finite element model of artificial disc replacement to observe the effects of the artificial lumbar disc replacement on zygapophyseal joints using biomechanical analysis of lumbar motion segment. The conclusion was that artificial lumbar disc replacement can keep the stress of motion segment at normal level, which can meet the needs of spinal functional reestablishment. 
Le Huec JC et al. [16] suggested for the first time the importance of the prosthesis positioning into the spine model by combining in vitro tests and finite element analysis. The finite element (FE) spine model was validated with the data from the in vitro tests. The effect of the prosthesis positioning on the motion behavior at L4 - L5 and on the inner loads over facets was evaluated in 4 configurations. The in vitro test results demonstrated that Maverick disc prosthesis provides near identical physiological function to a natural disc, restores stability of the spine, and preserves the segmental motion without undue stress on adjacent segments. H. Schmidt et al. [17] investigated the influence of different nucleus replacements on the mechanical response of the disc by using a variety of models including partial, full, over-sized, partially saturated, elastic and poroelastic solid replacements. Compared to intact, the under-sized implants should be avoided when using biphasic materials with properties similar to the native nucleus, whereas for elastic replacements both under- and over-sized implants should not be used.

With the improvement of modeling technology, finite element method can be widely used in the evaluation and improvement of clinical surgery and therapy, such as vertebroplasty [18], protruding after percutaneous vertebralplasty [19], and total lumbar disc replacement [15] [16]. Finite element method can further evaluate effects of surgery and reduce operation risk by simulating corresponding changes of the spine in different situations [20]. According to clinical trials after lumbar disc replacement, the short, mid, curative effect is positive, but the long-term curative effect still has a lot of uncertainty. The most common complications after lumbar disc replacement include heterotopic ossification [21], implant mechanical failure [22], adjacent segment and small joint degeneration [23], so the finite element analysis of artificial lumbar disc replacement needs to pay more attention to the long-term complications.

\subsection{Assessment of the Surgical Implementation Plan}

For lumbar disc degeneration, the clinical treatment commonly used is lumbar fusion which has been known as the "gold standard". The fusion segment will lose the activity of the lumbar spine and cannot achieve the functionality of the normal lumbar spine, so the adjacent segment degeneration is one of the common complications. The prominent advantage of artificial lumbar disc replacement is that the postoperative segment can retain intervertebral motion and reduce or even eliminate the occurrence of adjacent segment degeneration. A large number of clinical trials and finite element analysis have confirmed the development prospects of artificial lumbar discs [24]-[26]. Considering the different characteristics of lumbar fusion and artificial lumbar disc replacement, the different surgical methods are compared and analyzed using finite element method.

Shih-Hao Chen et al. [27] researched the biomechanical differences at the surgical and both adjacent levels following artificial disc replacement and interbody fusion procedures using finite element analysis. The conclusion was that the artificial disc replacement revealed no adjacent-level instability. However, instability was found at the 
surgical level, which might accelerate degeneration at the highly stressed annulus and facet joint. In contrast to disc replacement results, the posterior interbody fusion procedure revealed the possibility of accelerated degeneration of the annulus and facet joint at both adjacent levels. Zheng-Cheng Zhong et al. [28] evaluated the biomechanical behaviour of the lumbar spine under different preload application methods using hybrid-controlled finite element analysis. The finite element models of anterior lumbar interbody fusion (ALIF) and artificial disc replacement (ADR) were tested under three different loading conditions. This study concluded that the preload magnitude and application method affect the biomechanical behaviour of the lumbar spine. In addition, Min-Jie Rao and Sheng-Sheng Cao [25] compared the effectiveness and safety of artificial total disc replacement (TDR) with fusion for the treatment of lumbar degenerative disc disease (DDD). TDR showed significant safety and efficacy comparable to lumbar fusion at 2 year follow-up, and demonstrated superiorities in improved physical function, reduced pain and shortened duration of hospitalization. The benefits of operating time, blood loss, motion preservation and the long-term complications have still yet to be proven.

The common complications of traditional lumbar fusion are adjacent segment degeneration. The possible complications after lumbar disc replacement are heterotopic ossification, implant mechanical failure, adjacent segment degeneration and small joints degeneration. In order to evaluate whether lumbar disc replacement is superior to the traditional lumbar fusion, the following factors need to be considered: blood loss, operative time, and hospital stays after surgery.

\section{Future Development}

The above part reviewed the progress of finite element method (FEM) application in the field of artificial lumbar disc replacement. The future development of finite element method (FEM) in this field will be discussed here. In light of recent advances, the research focus and directions of finite element method are as follows: personalized design of prosthesis, postoperative behavior guide, and study of artificial lumbar disc replacement combined with fusion surgery.

With the advancement of modeling technology, finite element method has been increasingly used in the biomechanical study on artificial lumbar disc. A large number of studies show that the clinical outcomes of disc prostheses are good, while the design and application of artificial intervertebral disc remain to be improved. In addition, most of the finite element models of prostheses have not yet taken the personalized design into discount. Therefore, individualized design and dynamic optimization of the prosthesis will be the future development trend of the finite element method.

The long-term follow-up results of artificial lumbar disc replacement need large sample and more data to confirm, so it is important to study the behavior of postoperative regularity and provide postoperative behavior guidance. The simulation of stress distribution under the dynamic mechanical conditions is one of the new directions, especially considering the damage and vibration. The lumbar modal analysis could pro- 
vide a basis for the further dynamic analysis. Parameters such as natural frequency, modal shape and vibration amplitude of the lumbar spine would be helpful for the research of human movement behavior after artificial lumbar disc replacement.

In recent years, artificial disc replacement began to be applied instead of intervertebral fusion, but the long-term effects still need to be verified. It is necessary to investigate the effects of the hybrid operation method, such as artificial lumbar disc replacement combined with fusion surgery. At present, the study of the hybrid technique is still in its early days, but it is worth the attention of clinicians and researchers as a new operation method.

\section{Conclusions}

Finite element model studies have made and continue to make important contributions to our understanding of the biomechanics of intervertebral discs, reduced our dependence on animal and cadaver experiments, and act as an invaluable complement to biomechanical and clinical studies. Thus, there is no doubt that we have learned much in the past four decades from finite element model studies, and that future research looks even more promising [29] [30].

Using the finite element method, we can optimize the design of the artificial lumbar disc prosthesis, predict the risk of artificial lumbar disc replacement, evaluate the surgical methods, and prevent complications. However the finite element method also needs further improvement in the modeling and simulation results. Finite element analysis and in vitro experiments can complement each other, work together to promote the development and progress of biological mechanics. Future development and research areas include personalized design of the prosthesis, postoperative behavior guide, and artificial lumbar disc replacement combined with fusion surgery. In conclusion, finite element model studies have proven themselves as reliable and robust tools when combined with in vitro and in vivo measurements. The finite element method will play a more important role in the field of artificial disc replacement.

\section{References}

[1] Bai, W.-Y., Gu, H.-S., Liao, Z.-H. and Liu, W.-Q. (2013) Clinical Application of Artificial Lumbar Disc Replacement: Present and Future. Chinese Journal of Tissue Engineering Research, 17, 6321-6326.

[2] Blondel, B., Tropiano, P., Gaudart, J. and Marnay, T. (2011) Clinical Results of Total Lumbar Disc Replacement Regarding Various Aetiologies of the Disc Degeneration: a Study with a 2-Year Minimal Follow-Up. Spine, 36, E313-E319. http://dx.doi.org/10.1097/BRS.0b013e3181dfbc4e

[3] Van Steenbrugghe, M.H. (1956) Improvements in Joint Prosthesis. French Patent.

[4] Brekelmans, W.A.M., Poort, H.W. and Slooff, T.J.J.H. (1972) A New Method to Analyse the Mechanical Behaviour of Skeletal Parts. Acta Orthopaedica, 43, 301-317. http://dx.doi.org/10.3109/17453677208998949

[5] Belytschko, T., Kulak, R.F., Schultz, A.B. and Galante, J.O. (1974) Finite Element Stress Analysis of an Intervertebral Disc. J Biom Ech, 7, 277-285. 
http://dx.doi.org/10.1016/0021-9290(74)90019-0

[6] Su, J., Zhao, W.-Z., Chen, B.-Z., Li, B., He, S.-W. and Fang, X. (2010) Establishing Finite Element Contact Model of Human L1 L5 Lumbar Segments. Journal of Medical Biomechanics, 25, 200-205.

[7] Wang, J., Zhu, L.-X. and Cao, Y.-L. (2011) Finite Element Modeling of Human Lumbar Spine and Biomechanics Research on Internal Fixation. Chin J Orthop Trauma, 13, 589591.

[8] Qin, J.-S., Wang, Y., Peng, X.-Q. and Jiang, Y.-G. (2013) Three-Dimensional Finite Element Modeling of Whole Lumbar Spine and Its Biomechanical Analysis. Journal of Medical Biomechanics, 28, 321-325.

[9] Xiang, P., Du, C.-F., Zhao, M.-Y., Tian, S., Wang, L.-Z. and Fan, Y.-B. (2014) Modal Analysis of Human Lumbar Spine Using Finite Element Method. Journal of Medical Biomechanics, 29, 154-160.

[10] Ge, L. and Li, K.H. (2009) Digital Biomechanical Analysis of Artificial Disc in Disparate Material Models and the Relationship to Design Optimization. China Journal of Modern Medicine, 19, 1061-1064.

[11] Sans i Ballart, O. (2011) Finite Element Analysis of an Elastomeric Artificial Disc in Lumbar Spine: Study of a Parametric Artificial Intervertebral Disc under Different Load States and Positions in the Lumbar Spine. Thesis, Warsaw University of Technology, Poland.

[12] Borkowski, P., Marek, P., Krezesinski, G., Ryszkowska, J., Wasniewski, B., Wymyslowski, P. and Zagrajek, T. (2012) Finite Element Analysis of Artificial Disc with an Elastomeric Core in the Lumbar Spine. Acta of Bioengineering and Biomechanics, 14, 59-66.

[13] Vacas, F.G., Juanco, F.E., de la Blanca, A.P., Novoa, M.P. and Pozo, S.P. (2014) The Flexion-Extension Response of a Novel Lumbar Intervertebral Disc Prosthesis: A Finite Element Study. Mechanism And Machine Theory, 73, 273-281.

http://dx.doi.org/10.1016/j.mechmachtheory.2013.11.013

[14] Chen, X.-L., Hai, Y., Guan, L. and Liu, Y.-Z. (2015) Application of Finite Element Analysis in a Biomechanical Study on Artificial Lumbar Disc. Chinese Journal of Bone and Joint, 4 , 327-331.

[15] Wang, H., Xu, D.-Q., Hu, J.-Z., Li, K.-H., Lin, Z.-Y. and Lei, G.-H. (2010) Three-Dimensional Finite Element Analysis of the Zygapophyseal Joint Following Artificial Lumbar Disc Replacement. Journal of Clinical Rehabilitative Tissue Engineering Research, 14, 49154918.

[16] Le Huec, J.C., Lafage, V., Bonnet, X., Lavaste, F., Josse, L., Liu, M. and Skalli, W. (2010) Validated Finite Element Analysis of the Maverick Total Disc Prosthesis. J Spinal Disord Tech, 23, 249-257. http://dx.doi.org/10.1097/BSD.0b013e3181a5db24

[17] Schmidta, H., Bashkuev, M., Galbusera, F., Wilke, H.-J. and Shirazi-Adl, A. (2014) Finite Element Study of Human Lumbar Disc Nucleus Replacements. Computer Methods in Biomechanics and Biomedical Engineering, 17, 1762-1776. http://dx.doi.org/10.1080/10255842.2013.766722

[18] Rohlmann, A., Boustani, H.N., Bergmann, G. and Zander, T. (2010) A Probabilistic Finite Element Analysis of the Stresses in the Augmented Vertebral Body after Vertebroplasty. Eur Spine J, 19, 1585-1595. http://dx.doi.org/10.1007/s00586-010-1386-X

[19] Fei, Q., Li, Q.-J., Li, D., Yang, Y., Tang, H., Li, J.-J., Wang, B.-Q. and Wang, Y.-P. (2011) Biomechanical Effect on Adjacent Vertebra after Percutaneous Kyphoplasty with Cement Leakage into Disc: A Finite Element Analysis of Thoracolumbar Osteoporotic Vertebral Compression Fracture. National Medical Journal of China, 91, 51-55. 
[20] Yuan, F., Xue, Q.-H. and Liu, W.-Q. (2013) Recent Advances about Finite Element Applications in Spine Biomechanics. Journal of Medical Biomechanics, 28, 119-124.

[21] Park, S.-J., Kang, K.-J., Shin, S.-K., Chung, S.-S. and Lee, C.-S. (2011) Heterotopic Ossification Following Lumbar Total Disc Replacement. International Orthopaedics, 35, 197-201. http://dx.doi.org/10.1007/s00264-010-1095-4

[22] Punt, L.M., Visser, V.M., van Rhijn, L.W., Kurtz, S.M., Antonis, J., Schurink, G.W.H. and van Ooij, A. (2008) Complications and Reoperations of the SB CharitÉ Lumbar Disc Prosthesis: Experience in 75 Patients. Eur Spine J, 17, 36-43. http://dx.doi.org/10.1007/s00586-007-0506-8

[23] Siepe, C.J., Zelenkov, P., Sauri-Barraza, J.C., Szeimies, U., Grubinger, T., Tepass, A., Stäbler, A. and Mayer, M.H. (2010) The Fate of Facet Joint and Adjacent Level Disc Degeneration Following Total Lumbar Disc Replacement: A Prospective Clinical, X-Ray, and Magnetic Resonance Imaging Investigation. Spine, 35, 1991-2003. http://dx.doi.org/10.1097/BRS.0b013e3181d6f878

[24] Siepe, C.J., Heider, F., Wiechert, K., Hitzl, W., Ishak, B. and Mayer, M.H. (2014) Mid- to Long-Term Results of Total Lumbar Disc Replacement: A Prospective Analysis with 5 to 10-Year Follow-Up. Spine J, 14, 1417-1431. http://dx.doi.org/10.1016/j.spinee.2013.08.028

[25] Rao, M.-J. and Cao, S.-S. (2014) Artificial Total Disc Replacement versus Fusion for Lumbar Degenerative Disc Disease: A Meta-Analysis of Randomized Controlled Trials. Arch Orthop Trauma Surg, 134, 149-158. http://dx.doi.org/10.1007/s00402-013-1905-4

[26] Wei, H.-W., Chiang, Y.-F., Chen, Y.-W., Cheng, C.-K. and Tsuang Y.-H. (2012) The Effects of Different Articulate Curvature of Artificial Disc on Loading Distribution. J Appl Biomater Funct Mater, 10, 107-112. http://dx.doi.org/10.5301/JABFM.2012.9258

[27] Chen, S.-H., Zhong, Z.-C., Chen, C.-S., Chen, W.-J. and Hung, C.H. (2009) Biomechanical Comparison between Lumbar Disc Arthroplasty and Fusion. Medical Engineering and Physics, 31, 244-253. http://dx.doi.org/10.1016/j.medengphy.2008.07.007

[28] Zhong, Z.-C., Hung, C.H., Lin, H.-M., Wang, Y.-H., Huang, C.- H. and Chen, C.-S. (2013) The Influence of Different Magnitudes and Methods of Applying Preload on Fusion and Disc Replacement Constructs in the Lumbar Spine: A Finite Element Analysis. Computer Methods in Biomechanics and Biomedical Engineering, 16, 943-953. http://dx.doi.org/10.1080/10255842.2011.645226

[29] Schmidt, H., Galbusera, F., Rohlmann, A. and Shirazi-Adl, A. (2013) What Have We Learned from Finite Element Model Studies of Lumbar Intervertebral Discs in the Past Four Decades. Journal of Biomechanics, 46, 2342-2355. http://dx.doi.org/10.1016/j.jbiomech.2013.07.014

[30] Wang, D.-Y., Xi, C.-Y., Yang, H., Xia, S.-Q. and Yan, J.-L. (2015) New Progress and Application of Finite Element Analysis Technology in Lumbar Spine Biomechanics. Progress in Modern Biomedicine, 15, 1794-1797. 
Submit or recommend next manuscript to SCIRP and we will provide best service for you:

Accepting pre-submission inquiries through Email, Facebook, LinkedIn, Twitter, etc.

A wide selection of journals (inclusive of 9 subjects, more than 200 journals)

Providing 24-hour high-quality service

User-friendly online submission system

Fair and swift peer-review system

Efficient typesetting and proofreading procedure

Display of the result of downloads and visits, as well as the number of cited articles

Maximum dissemination of your research work

Submit your manuscript at: http://papersubmission.scirp.org/

Or contact jbise@scirp.org 